\title{
In-Home Continuing Care Services for Substance Use Affected Families
}

By: Kenneth J. Gruber and Thomas W. Fleetwood

Gruber KJ, Fleetwood TW. (2004). In-home continuing care services for substance use affected families. Substance Use \& Misuse. Jul;39(9):1379-403. Review. PubMed PMID: 15462236.

This is an Accepted Manuscript of an article published by Taylor \& Francis in Substance Use \& Misuse on July 2004, available online: $\mathrm{http}$ ://www.tandfonline.com/10.1081/JA$\underline{120039395}$

\begin{abstract}
:
The role of in-home work with substance use affected family members has great potential for addressing family and personal issues that are often not well addressed by continuing care interventions that involve limited contact with the family and the impact alcohol and other drug "abuse" has on the family environment. This article reviews the importance of involving the family in the recovery process and offers comparative advantages of an in-home visitation approach for assisting the substance user with maintaining substance use avoidance, reintegrating with the family, and addressing unresolved family Issues affecting children and spousal relationships.
\end{abstract}

Keywords: After care | Continuing care | Recovery | Case management | Resilience | Risk factors | Protective factor | Harm reduction

\section{Article:}

Recent statistics indicate that alcohol and chemical dependency continues to affect a significant number of individuals and families. Findings from the 2001 National Household Survey on Drug Abuse (Substance Abuse and Mental Health Services Administration. 2002) indicated that in the United States, 16.6 million persons (age 12 or older) were identified with dependence or abuse of either alcohol or illicit drugs. The survey also revealed that in the 12 months prior to participation in the survey, an estimated 3.1 million persons received some kind of treatment (including participation in self-help groups) related to their alcohol or drug use problem. Unfortunately, research evidence indicates that completion rates in treatment programs are low and even among treatment completers, relapse is likely (Connors et al.. 2001; LaFave and Echols. 1999).

Because substance dependency and addiction is often difficult to overcome, supplemental treatment in the form of aftercare or continuing care can be an effective way to support steps toward and maintaining recovery. Aftercare/continuing care is based on the notion that continuing assistance following primary substance user treatment can remove or reduce factors associated with relapse and strengthen factors associated with the maintenance of sobriety (Hawkins and Citlalano. 1985). As a supplemental or complementary service to primary treatment, aftercare/continuing care often stands alone as the determining experience for recovery or relapse (Donovan. 1998; Margolis and Zweben. 1998). 
This article presents a discussion of the advantages of an in-home approach to providing aftercare/continuing care services to substance use affected parents. The remainder of the article discusses the importance of intervention services following primary substance user treatment and the impact that substance "abuse" has on families, especially on parents and its impacts on their children. The article emphasizes the importance of families as participants and resources in recovery and argues for a family centered home-based approach to delivering recovery support services to addicts and their families. Finally, the article reviews an application of one homebased model and discusses implications for applications of this approach to recovering alcoholics and drug addicts with parenting and other family responsibilities who might not otherwise be able or willing to participate in aftercare/continuing care services to maintain their recovery and avoid relapse.

\section{Continuing care and recovery}

The role of continuing care as a critical component to recovery has increased as the duration and scope of primary substance user treatment has decreased. It has been noted that such services should be integrated into the continuum of care as part of the treatment plan rather than be an "add on" option (Donovan, 1998), But. continuing care services, because of their lack of formal inclusion in primary treatment programs and plans, often are avoided or clients fail to follow through in attending and in active participation in service goals. Despite these difficulties. There is evidence that involvement in continuing care results in longer periods of abstinence and appropriate social skill behavior (Donovan. 1998). Moreover, when combined with behavioral marital therapy as an adjunct to outpatient treatment, continuing care has been found to result in more positive recovery outcomes (fewer days of drug use. longer periods of abstinence, and fewer drug use related arrests and re-hospitalizations) (Fals-Stewart et al.. 1996; O'Farrell et al., 1993).

Continuing care services focus primarily on helping the substance user achieve reduction of harmful consequences (harm reduction) associated with drug addiction and alcoholism through abstinence and avoidance of self-destructive behavior (Denning. 2001; Marlatt and Tapert, 1993; Marlatt and Witkiewitz, 2002). Additionally, it is becoming increasingly apparent that addiction recovery involves more than just focusing on preventing relapse, but equally on the restoration of the individual as a productive worker, citizen., and family member. Successful recovery effects should result in positive consequences for employment, life satisfaction, social functioning, family cohesion, and marital harmony (McCrady and Epstein, 1996; Sullivan et al., 1992; Wynne et al.. 19\%).

\section{Substance abuse in families}

"Substance abuse" often develops within a family context and within this context its destructive effects are likely to have their most harmful impact. Family "substance abuse" is frequently accompanied by other problems such as mental illness, domestic violence, economic difficulties, housing problems, and security issues related to residence in risky neighborhood environments (Magura and Laudet, 1996; Semidei et al., 2001). Families affected by "substance abuse" are at great risk of disruption and dissolution. Children may suffer the most from living in 
an unstable home and face the uncertainty of out-of-home placement (Gregoire and Schultz, 2001). The issue of "substance abuse" in families is a significant one because it often transcends multigenerational lines if left unacknowledged and untreated (McCrady and Epstein, 1996; Steinglass et al.. 1987; Wynne et al.. 1996).

An emerging emphasis on strengths-based perspectives suggests that the impact of parental substance use can be considered in terms of its impact on imputed risk and protective factors related to child well-being (Glantz and Johnson. 1999; Voydanoff and Donnelly. 1998). Risk factors are posited conditions or variables associated with the occurrence of negative outcomes such as ill health, unsatisfactory well-being, and poor social performance. Protective factors are the posited mechanisms and processes that promote positive outcomes resulting in good health, satisfactory well-being, and competent social performance. Parental substance use often leaves children unprotected against risks of psychological, emotional, and physical harm.

\section{Impact of parental substance abuse}

The parenting ability of substance user parents is frequently adversely affected by their use of drugs or alcohol. There is mounting evidence of a link between child maltreatment and parental substance use (Magura and Laudet. 1996; Sheridan, 1995; Whileside-Manseil et al., 1999) and subsequent child behavior problems (Chassin et al.. 1996; Magura and Laudet, 1996; O'Farrell and Feehan. 1999). Though chemical dependency is not an exclusive causal factor, its association with other predisposing personal and family factors is often a determining factor for neglect of, or aggression directed toward, children. Substance use negatively affects parents' ability to be (a) reliably attentive, (b) appropriately responsive, (c) effectively involved, (d) proper disciplinarians, (e) adequate protectors, and (f) physically, emotionally, and psychologically available and/or accessible for their children (Magura and Laudet, 1996).

This impact on parenting means that substance use intervention with substance affected parents involves more than just addressing the substance user's addiction. Yet. traditional treatment and recovery approaches typically have encouraged substance users to focus their time and energy on themselves and to set aside concerns about family or children to "avoid" interfering with addressing their addiction (Magura and Laudet, 1996; OTarrell and Fals-Stewart. 1999), This perspective assumes a disease-model perspective that emphasizes that in order to best address addiction a substance user needs to concentrate on one's self separate and apart from family and other significant persons in the addict/alcoholic's life. But this view is neither practical nor realistic when applied to substance using parents. First, it is important to recognize that the addicted parent cannot be treated in isolation because the addiction did not occur in isolation. Second, it ignores the positive impact which the inclusion of supportive family members can have on the treatment/recovery process. Third, separation from family does little to reinforce the responsibilities parents have for their responsibilities to their families, especially to their children (Azzi-Lessing and Olsen, 1996; Killeen and Brady, 2000).

\section{Role of family in substance abuse recovery}

It has been well established that family members often have a central role in the course of alcohol or drug addiction (Margolis and Zweben, 1998; Moore and Finkelstein. 2001; OTarrell and Fals-Stewart, 1999; Steinglass et al., 1987), its successful treatment (Edwards and Steinglass, 1995; Fals-Stewart et al., 1996), and maintenance of recovery (Brown and Lewis. 
1999; Carten. 1996; Donovan. 1998; Higgins et al., 1994; O'Farrell et al.. 1993). This role has both negative and positive implications for treatment and post-treatment outcomes. Problems involving other family members or maladaptive family relationships that may have been overshadowed by the substance use may become more evident when drug use is not an issue (Haber, 2000). Steinglass, Bennett, Wolin, and Reiss (Steinglass et al.. 1987) identified this readjustment process as family reorganization and emphasize that this process is a major determinant of a family's interaction patterns and adaptive responses to the substance affected family member once the pattern of substance using has changed.

The family's involvement is often a key determinant of an individual's commitment and ability to achieve recovery. There is increasing evidence that family involvement in recovery interventions is often associated with positive recovery progress and fewer and less serious episodes of relapse (Edwards and Steinglass, 1995; Higgins et al., 1994; Hohman and Butt. 2001; Margohs and Zweben, 1998; Moore and Finkelstein, 2001; O'Farrell and Feehan. 1999). By contrast, dysfunctional family functioning has been found to relate to poor prognoses for recovery (Costantini et al., 1992; Haber, 2000; McCrady and Epstein, 1996). Family involvement can be an incentive or support for motivation to change (Connors et al., 2001; Edwards and Steingluss, 1995; MarkUt and Taperl, 1993; Wynne et al., 1996); therefore, families should be engaged in the recovery process to minimize the risk of relapse (StevensSmith. 1998) and intervention models should include treatment and recovery component that address recovery in the context of the total family (Gregoire and Schultz, 2001; Margolis and Zweben, 1998; McAlpine et al., 2001).

Substance users and their families often need additional intervention, support, and education following the addict's participation in a primary (i.e., in-patient or intensive out patient) treatment program. Typically, in the aftercare phase following primary treatment services, participants are offered group therapy or are directed to 12-step mutual-help sponsorship programs like A.A. and N.A. Most continuing care provided in outpatient settings is unequipped to offer comprehensive family services. When families are included, their role is usually limited to addressing couples or family therapy issues or for supporting the substance user's participation in continuing care (Edwards and Steinglass, 1995; O'Earrell and Fats-Stewart, 1999). Moreover, these services generally do not provide transportation assistance or address family/child care issues that can interfere with recovery plan compliance (Semidei et al.. 2001; Sullivan et al.. 1992; Tracey. 1994).

The concept of family resilience is relevant here. There are two aspects of resilience that warrant consideration. First, there is resilience that stems from an individual's personality traits, physical characteristics, and abilities. The second aspect relates to the functional status of an individual's family and the processes and adaptability level of the family (McCubbin et al.. 1999; Voydanoff and Donnelly. 1998). An emphasis on individual and family resiliency can help families to withstand and rebound from disruptive life experiences. The concept of family resilience provides a context by which families can be viewed as confronting and managing disruptive experiences, buffering stress, effectively reorganizing, and moving forward with their lives. It emphasizes the value that family interactions have on affecting immediate and long-term adaptation for family members as individuals and the family as a whole (Walsh, 1998).

\section{Family-centered approach to recovery}


Lack of transportation, child care, and attending to their children's needs often prevent substance abusing parents, especially mothers, from keeping appointments and following through on changing conditions in their lives that support or maintain their addiction or addiction lifestyle (Azzi-Lessing and Olsen. 1996; Uziel-Miller and Lyons, 2000). Female substance users often are at an additional disadvantage to benefit from traditional continuing care efforts due to their lack of marketable job skills, single parenting responsibilities, limited access to child care, emotional and social isolation, financial difficulties, stress, negative life experiences (e.g., partner physical abuse) and psychological problems relating to depression and anxiety (Azzi-Lessing and Olsen, 1996; ICilleen and Brady, 2000; Magura and Laudet. 1996). An added barrier is their fear that admitting to using substances may result in child welfare services placing their children out of the home (Tracey, 1994).

Thus, an effective system to address these issues is likely to be one that has the family as the center of concern and service (Nelson-Zlupko et al., 1996; Whiteside-Mansell et al., 1999) and one that recognizes that recovery is likely to be a long process and continuing care support is necessary for both the substance user and the family (Azzi-Lessing and Olsen. 1996; Olsen, 1995). For substance using parents, their ability to adequately care for and nurture their children is likely dependent on their continuing to have access to treatment and ongoing support services. A family-centered home-based approach provides these parents a treatment/support option that enables them to remain in their homes with their families and address the problems that the addiction has caused (Azzi-Lessing and Olsen, 1996). A distinctive feature of a family-centered approach is that it provides intervention services in the context of family preservation where the focus is on both recovery of the substance user parent and supporting the integrity and continuity of the family. Family preservation services help families with using nonclinical services to buttress gains in recovery by building support networks among relatives, friends, children, church and other social group members (Tracey. 1994).

Collaboration between child welfare agencies and substance user treatment is essential if families are going to have a realistic chance for recovery and for their children to grow up and thrive in a substance use free family environment (McAlpine et al, 2001). Often in situations where children are removed from custody, parents are given the opportunity to regain custody if they demonstrate significant progress towards recovery and the ability to parent. They are then left to negotiate with different treatment systems (i.e., child welfare and substance user treatment) which frequently are not actively collaborating or even coordinating their goals to best assist the substance user client. Though the long-term effectiveness and effectiveness with specific groups has not been well established, there is a growing consensus that a familycentered approach includes features that are effective with addiction and substance use recovery. These include: easy accessibility, intensive home-based services, family member involvement, client involvement in treatment planning, cultural sensitivity, and non-intrusive and nonstigmatizing interventions (Carten, 1996). Specific foci ofa family-centered approach are presented in Table 1.

- Support services to working parents

- Access to recovery services that otherwise may be difficult to access due to transportation and child care needs

- Parenting and family skills training

- Assessment of parent behavior in the context of risk to their children 
- Involvement of parents, especially mothers who might otherwise refuse treatment/aftercare

- Problem solving for parents at risk of losing custody of their children

- Problem solving for parents who have lost and seek to regain custody

- Behavioral and emotional counseling at risk parents before serious harm to their children

- Individual needs of the substance abuser and of family members

- Engagement of family members who may deny the addiction or interfere with the recovery process

- Involvement strategies to build a trusting relationship with the substance abuser and the family

- Concrete services (e.g., financial assistance, transportation, child care)

- Referral to and connection with other helping sources and resources

\section{Home visitation and substance use avoidance}

A common criticism of substance use interventions that emphasize relapse prevention is that there is too little attention paid to helping the addict or user modify the post-treatment environment (Donovan, 1998). It has also been suggested that treatment success will be enhanced if greater attention is placed on social functioning and altering the environmental context that may encourage or permit drug or alcohol use (Sullivan et al., 1992). Thus, unless intervention services are extended into the abuser's "real" world environment, gains attained in treatment may not persist. It has been suggested that case management services may be needed to provide a transitional bridge between being in a structured treatment setting and helping addicts adapt to being on their own in the general community (Gray, 1993; Patterson et al,, 1997; Sullivan et al., 1992), While the "best practices" for achieving this has not been well established, services delivered in a home-based context have found positive results (Gruber et al., 2001).

Some believe that a home based approach is too costly for the benefits it might deliver. One study concluded that home visits to alcohol dependent male veterans were not a cost effective way to deliver aftercare services (Gilbert, 1988). In a review of studies (Donovan. 1998) reporting positive impact on case management outcomes one author concluded,

Case management approaches in general. and home visit procedures in particular, are considered to be quite expensive to conduct in terms of therapist time and transportation costs. The staff intensity and resultant costs may make such approaches impractical since most treatment programs lack adequate resources to provide case management support. (p. 331)

But case management is an important organizing tool when services must be accessed across service systems, accessible through client initiation, or established through advocacy or negotiation (Sullivan et al., 1992). Some populations may be more suitable and more receptive than others to home visitation as an intervention service. Home visiting programs to address parental substance use related problems and their impact on the family are increasingly recognized as an important method for reaching the substance user parent (Carten, 1996; Magura and Laudet, 1996; Nelson-Zlupko et al,, 1996). The advantages of this approach overcome 
many of the barriers that prevent these parents from seeking and getting the supportive help they need. Investigators (Black and Nair, 1994) found in a 18-month clinical trial study of 43 new mothers with histories of cocaine or heroin use that home visitation by a nurse was associated with their ability to maintain drug-free status and to practice positive parenting and child care behavior. Another group of researchers (Patterson et al., 1997) found in a five year follow-up of a sample of alcoholics that those who received 12 months of home visitation aftercare services from a community psychiatric nurse following inpatient treatment reported more positive outcomes, including greater percentages of abstinence, fewer blackouts, less gambling, and better hospital meeting attendance than a comparison group that received standard outpatient aftercare. Other investigators have demonstrated that home visitation continuing care services are effective in reaching parental substance users as they work on reintegrating themselves back wilh their families and communities (Gruber et al.. 2001). One additional study found that elements of the home setting were more salient for determining relapse than either social or work settingwhich suggests that the interventions in the home of the recovering addict may be very effective in preventing relapse (Walton et al.. 1995).

\section{Advantages of home visitation intervention}

Home visiting involves applying a family systems approach which focuses attention on family interaction patterns that encourage or sustain substance use. When a part of the family system changes, it impacts all other parts of the system. Family systems are best observed in their natural environment (Stevens-Smith. 1998). By approaching substance use recovery through the family the intervention can focus on:

- addressing the dysfunctional part of the family system that has evolved to protect and accommodate the substance using family member

- uncovering the barriers of denial and subterfuge that families will engage in to avoid addressing the "problem" or the sustaining behaviors

- examining family rules, roles, and behaviors that might mask or perpetuate dysfunctional family behavior

- rehabilitating the substance user to return to a functional lifestyle unimpeded by drug use (De Leon et al., 3001).

A major purpose of this article is to provide professionals who work with substance affected individuals and their families a rationale for considering providing home-based delivered substance user continuing care services. While there are limitations and resource costs to providing recovery services in the nontraditional manner of "in the client's home" home visitation services offer a range of advantages over an exclusively office or clinic based continuing care service approach. The advantages are both therapeutic and practical. A comprehensive home visitation service model can ensure that the recovering substance user and family members receive a range of services that emphasizes an holistic approach to abstinence., understanding, and recovery. Table 2 provides a comparison of features of a typical office/clinic approach with a comprehensive home visitation model tor working with recovering substance users.

The major advantage of a home-based approach to recovery is that it provides opportunities to observe and engage in relevant recovery activities. The approach also 
encourages a more "inclusive" relationship between the family and the worker so that the focus extends beyond just the problems of the substance user and centers more on the family as the object of recovery. This provides the worker a larger group of "clients" for a given case, but it also provides opportunities to connect with the family on different levels as across a variety of issues. This multiple perspective is likely to give insight into the recovery barriers as well as identify family strengths that can be used to guide and support the family in maintaining recovery.

The features compared in Table 2 point to the potential strengths of a home visitation approach to substance user continuing care services. Barriers to accessing aftercare services such as lack of transportation or family issues are virtually eliminated when services are delivered to the substance user and the family in their home. Home visitation enables a worker to spend adequate time with an user and family as well as visit them at times both convenient and critical to the recovery process. Being in the home gives the worker opportunities to talk with and observe the family about issues related to recovery as well provide instruction and guidance on family issues that may be less obvious but relevant to the family's successful functioning and long-term recovery success.

\section{An in-home application: The Bridges Model}

One example of a home visitation continuing care program for substance-affected families is the Bridges Program (Gruber et al.. 2001). The Bridges Program is an intensive inhome support program aimed at increasing the likelihood of long-term recovery by focusing on the early transition from a more intensive substance use focused treatment regimen to other adjustment issues related to family, work, and the community. It grew out of a recognition that too many substance using parents were risking the dissolution of their families due to their drug or alcohol use and to the family environment altering changes that often occur during the recovery phase. The program serves families in which at least one child is determined to be at risk of harm or out-of-home placement stemming from parental substance use. The program is based on an integrated model of relapse prevention and family preservation.

\begin{tabular}{|c|c|c|}
\hline Features & Orficejelinic & In-home \\
\hline Intervention focus & $\begin{array}{l}\text { Primarily client substance tase and avoidance } \\
\text { behavior }\end{array}$ & $\begin{array}{l}\text { Family focus including felationskips, rituals } \\
\text { and rules uffecting substance use and } \\
\text { recovery }\end{array}$ \\
\hline Recovery focus & Primarily client focused & Family-centered \\
\hline Setting & Formul-institutional/ time and event regulated & $\begin{array}{l}\text { Informal-client/family determined-relaxed } \\
\text { familiar }\end{array}$ \\
\hline Therapeutic atmosphere & $\begin{array}{l}\text { Artificial settine/limited clinical cues- } \\
\text { primarily from client }\end{array}$ & $\begin{array}{l}\text { Real setting extensive clinical cues from client, } \\
\text { client family, and the home }\end{array}$ \\
\hline Transportation & Requires transportation access & Servioes delivered to client and family \\
\hline Contact availability & Limited to offleciclinic bessiness hours & Available $24 \mathrm{~h} / 7$ days a week \\
\hline Contaci frequency & $\begin{array}{l}\text { Office appointmear determined (availability } \\
\text { limited) }\end{array}$ & As needed basis favailability $24 / 7$ ) \\
\hline Contact occurrence & $\begin{array}{l}\text { Appointment and session length determined/ } \\
\text { usually only during normal business hours }\end{array}$ & $\begin{array}{l}\text { Need and client,family participation deter- } \\
\text { mined iscluding evening and weekends }\end{array}$ \\
\hline Contact duration & Session knyth preiletermined & $\begin{array}{l}\text { Contact time elient/family need and conditions } \\
\text { determined }\end{array}$ \\
\hline $\begin{array}{l}\text { Barriers to therapeutic } \\
\text { relationship }\end{array}$ & $\begin{array}{l}\text { Primurily dependent on joining with client on a } \\
\text { scheduled session basis }\end{array}$ & $\begin{array}{l}\text { Relationship development is not impeded by } \\
\text { lack of ucoess to client/relationship devel- } \\
\text { opment is assisted by worker availahility } \\
\text { and time with family }\end{array}$ \\
\hline Intensity & $\begin{array}{l}\text { Limited by session length and involyed parties } \\
\text { present }\end{array}$ & $\begin{array}{l}\text { Determined by client/family needs and condi- } \\
\text { tions requiring type and length of service } \\
\text { contact }\end{array}$ \\
\hline
\end{tabular}




\begin{tabular}{|c|c|c|}
\hline Service participation & $\begin{array}{l}\text { Identified client,family members when } \\
\text { arranged }\end{array}$ & $\begin{array}{l}\text { Identified client/family members routinely } \\
\text { involved }\end{array}$ \\
\hline Crisis availahility & $\begin{array}{l}\text { Limitod to office hours and on call after hour } \\
\text { services }\end{array}$ & As needed basis (availability $24 / 7$ ) \\
\hline Environmental costext & $\begin{array}{l}\text { Client,family observed in office/clinic } \\
\text { envirunment }\end{array}$ & $\begin{array}{l}\text { Chent/farsily observed in home environment } \\
\text { (natural milieu) }\end{array}$ \\
\hline Participation barriers & $\begin{array}{l}\text { Likely limited faffected by transportation } \\
\text { access, work and family schedules and stigma } \\
\text { of coming to officejelinic for treatment) }\end{array}$ & $\begin{array}{l}\text { Fewer barriers becouse transportation and } \\
\text { personal and family schedules are } \\
\text { addressed,identification as a client is more } \\
\text { limited due to bome visitation }\end{array}$ \\
\hline Concrete services & Limited provision of these kinds of services & $\begin{array}{l}\text { Reutine provision of assistance relatine to } \\
\text { transportation, childcare, and other human } \\
\text { services }\end{array}$ \\
\hline $\begin{array}{l}\text { Follow-sp on clieat } \\
\text { recovery actions }\end{array}$ & $\begin{array}{l}\text { Limited to client report and observation in } \\
\text { office iclinic }\end{array}$ & $\begin{array}{l}\text { Observations of client actions made in sig- } \\
\text { mificant settings where client lives, works, } \\
\text { and recreates }\end{array}$ \\
\hline Advocacy involvement & Usaally limited to contact by phone and mail & $\begin{array}{l}\text { In-person advocate us well as phone and mail } \\
\text { contact }\end{array}$ \\
\hline Family involvement & $\begin{array}{l}\text { Limited to when family members come in for } \\
\text { sessions }\end{array}$ & Included on-site; routinely included \\
\hline $\begin{array}{lr}\text { Parenting } & \text { behaviof } \\
\text { assessment } & \text { and } \\
\text { intervention } & \end{array}$ & $\begin{array}{l}\text { Limited to client reports and observation when } \\
\text { children are present }\end{array}$ & $\begin{array}{l}\text { Increased opportunities to observed and } \\
\text { resommend changes in natural environment } \\
\text { with naturally occurring reinforcers }\end{array}$ \\
\hline Spousal relationships & $\begin{array}{l}\text { Limited to client reports and observation when } \\
\text { spouse is present }\end{array}$ & $\begin{array}{l}\text { Increased opportunities to observe and recom- } \\
\text { mend changes in family systems relating to } \\
\text { spousal relations }\end{array}$ \\
\hline
\end{tabular}

The program is family centered and is designed to help children/spouses understand substance use and its impact on the family.

Because substance user parents frequently exhibit unrealistic expectations of themselves and other family members, the risk to the family's dissolution is high. The program addresses issues such as child and adolescent development to minimize the negative impact of these expectations. It also focuses on improving other aspects of parent-child relations through an emphasis on functional communication and parental responsibility, reducing parenting stress and managing anger.

Services address three basic primary goals (1) to help the substance user in maintaining the recovery process, (2) to help the family address their roles and behaviors relating to the abuser's recovery, and (3) to provide family preservation and/or family reunification services. The Bridges Program helps the recovering client and his or her family develop skills and support activities to avoid relapse and develop a support network within their home community to facilitate the recovery process. Recovering parents are helped to reintegrate with their children and other family members, develop relationship and employment skills, and obtain community resources. The intervention curriculum focuses increasingly on the recovering client's selfawareness and developing cognitive and behavioral skills to avoid situations and/or conditions that might lead to relapse. The program connects clients and their families with mutual help groups (such as Alcoholics Anonymous, Narcotics Anonymous, or Al-Anon). teaches problem solving skills, and helps clients broker access to other programs and other specialized services (e.g.. Parents' Anonymous, vocational rehabilitation) available in the community. It also provides advocacy for the client with the judicial system and involved community agencies (e.g.. child protective services, mental health). A strong emphasis is placed on meeting ecological needs of the client and family, which may include assistance in the areas of housing, transportation, child care, recreation, education, health care, and employment.

Clients receive services over an eight-to-12-week period. Contact time includes four to six hours of direct services each week with the client and the family in their home and community. There is an emphasis on flexibility in scheduling the delivery of services which 
includes availability for evening and weekend direct service contact. Follow-up and crisis services are provided on an as needed basis for up to six months following termination of the primary service period. A "substance abuse" specialist, a master's level social work clinician with certification in "substance abuse," provides the services.

The program's intervention domains were selected to form a holistic practice model that would support individual and family relapse prevention work. Selection of the specific model components were guided by the relapse prevention model approach (Daley and Marlatt, 1992; Daley and Raskin. 1991: DeJong. 1994) and by the addiction recovery approach (Gorski and Miller, 1988). Additionally, the specific domains that make up the core of the model were selected to achieve the service focus of linking parental recovery with family support action. The domains and their respective components were included on the basis of their relationship to family and parent functioning and to their identified significance in contributing to relapse prevention.

The program mode! addresses functioning in four domains:

- Individual Actions \& Cognitions.

- Individual Recovery Actions,

- Family Actions \& Cognitions, and

- Family Recovery Actions.

The Individual Skills \& Cognitions domain includes behaviors and thinking patterns of the substance user that represent facets of functioning that are essential to engaging in a lifestyle not dependent on alcohol or drug use. The Individual Recovery Actions domain includes behavioral changes that the substance user must successfully integrate into their daily life in order to achieve/maintain sobriety and avoid use of alcohol or drugs. The Family Skills \& Cognitions domain includes behaviors and thinking patterns of the substance user's family that represent facets of family functioning that are essential to providing the support and structure that the user needs in order to be able to engage in a lifestyle which is not dependent on alcohol or drug use. The Family Recovery Actions domain includes actions that the family of the substance user need to take in order to understand and assist the recovering client achieve/maintain sobriety and avoid use of alcohol or drugs. Measurement of achievement in these domains is done through a series of assessment questions directed at aspects of each domain at case opening, case closure, and six weeks following the closure of the case. Components are scaled on a motivation to change/achievement of change dimension fashioned after the stages of change model of DiClemente and his colleagues (e.g., see Connors et at. 2001. Prochaska et al. 1992). The domains and their components are used in the development and implementation of the treatment plan which addresses family functioning and relapse prevention issues. Level of functioning within each domain is addressed so that the focus on the work with the family is to establish a strong link between family behavior and support actions and the substance affected parent's functioning and recovery actions.

\section{Implications for continuing care and recovery}

Substance affected families often need assistance for issues that encompass many dimensions of family life. These families are vulnerable to serious destabilization or dissolution if their multiple needs are not addressed. When services are compartmentalized to address a 
specialized issue like substance use. it is likely that insufficient attention is given to the person as a family member or to the social context of the family. Therefore, interventions that can redirect attention to these larger contexts have great potential for fostering positive change. To effectively address the multi-faceted issues associated with chemical dependency, we must strive to develop new and creative treatment approaches and recovery protocols. These efforts must recognize that a substantial number of individuals and families affected by substance use may not be able to benefit from traditional or institutionalized substance user treatment interventions.

Interventions that enhance "social capital"— the development of a reliable and capable support network - as a resource for addressing substance use have great potential for producing substantial and lasting change (Granfield and Cloud, 2001). Such approaches should look to family members and others as facilitators in the change process and include their involvement whenever possible and practical (Denning, 2001). Approaches that emphasize improved social and personal functioning over absolute abstinence are frequently advantageous as treatment options (Sullivan et al., 1992). Harm reduction approaches to substance use treatment and continuing care may be more compatible with family involvement approaches because it places an emphasis on the often more realistic and achievable goal of substance use reduction rather than absolute abstinence (Marlatt et al., 2001). Other family members are likely to be more inclined to view themselves as having the capacity to help the substance using family member if the "problem" is one of behavior rather than disease and the goal being of degrees of change rather than absolute change.

There are differing viewpoints as to what constitutes a positive outcome for substance user treatment and recovery. In part, this difference stems from differences in service providers' treatment philosophy, educational discipline, training and practice experience, personal experience, institutional or organizational requirements, and funding. Determination of improved client functioning (efficacy) also is dependent on the goals of the intervention service and the ability of the therapeutic experience to produce desired changes such as abstinence or avoidance of settings that increase risk of relapse. The complexity of these factors often make it difficult to select critical indicators of treatment effect and often lead to conclusions that an intervention may not be effective if the identified target outcome is not achieved, even if other progress related factors (e.g., increased family support, reduced family tension, participation by family members in therapy or self-help group programs) are evident (McEldowney and Heilman, 1999).

Untreated or relapsed alcoholics and addicts pose a substantial cost to families and communities, particularly if they are unwilling or lack the resources to participate in treatment and recovery programs (Marlatt et al., 2001). Thus, intervention approaches like in-home visitation that can reach and engage these individuals in the recovery process hold potentially great value as both a treatment service delivering and cost savings strategy. Treatment retention is improved when services are specialized to the needs of the client. Programs that "take the services to the client" have great potential for engaging "treatment resisters" and others who for a myriad of reasons (e.g., work schedule, transportation access, family demands) will not participate in aftercare programs operated within a clinic or other structured program environment.

For continuing care to be most effective in its ability to reach and impact substance affected parents with children living in the home, the approach needs to maintain flexibility in both its structure and its clinical orientation. A home visitation family centered approach has the potential to reach those who might otherwise not have access to services they should have the opportunity to receive. Although some have concluded that a home visitation approach is too 
expensive in terms of resources and measured outcomes, this conclusion fails to acknowledge the costs (including financial, emotional, and social) that accrue when families are disrupted, children are forced to live away from their parents, and the lives of all are forever changed by the family's dissolution. The presumption that home visitation may be too expensive also ignores the tremendous cost burden that addicts place on communities in terms of ongoing medical and mental health services, time in the correctional system, demand for legal and social services, and lost work productivity.

\section{Future directions}

In-home continuing care for substance affected parents represents just one type of continuing care service with possible applications for a variety of intervention settings. Another specialized group of substance users who might greatly benefit from in-home continuing care services are recent parolees from prison. There is strong evidence that substance affected individuals leaving prison are at great risk for relapse and a return to criminal activity. Studies show that recidivism for parolees is high if their drug addiction and/or substance u.se related problems are not addressed. This is most likely to be true for those who do not successfully complete treatment while in prison or who find themselves with little or no financial resources, without a job. lacking vocational training, and in need of a permanent place to live (Brown et a!., 2001: Hall et al.. 2001). In the case of recovering offenders the period oi' time just after the release from prison is critical to the successful avoidance of the commission of criminal activity and re-imprisonment. Prison parolees often reject post-release treatment because they believe that they can remain drug free on their own and want to avoid structured programs where they are "told what to do" (Hall et al., 2001; Hiller et al.. 1999). Programs that can overcome these "obstacles" have potential for reaching at least some of those considered "unreachable" for recovery assistance.

According to McKay (2001), there is a "relative paucity of continuing care studies" (p. 211). Much remains to be determined. Despite their presumed value and effectiveness, gaps still exist about the types of continuing care services that are associated with the best outcomes, who best benefits from which kinds of services, what services are most critical to positive outcomes, and how best to optimally combine continuing care with primary treatment services.

Finally, it is our contention that the optimal path to recovery is through the family because often the family is where the addiction and/or use has its most impact and where resources to support recovery are likely to be found. Therefore, we should look to families as sources of strength and resources for recovery. It is the challenge of all health professionals to provide the best care for their clients and to recommend and refer them to the services that can best care for their needs. Home visitation programs are ideal as care models because they can deliver a wide range of services to substance users and their families through different recovery options and modalities to help them not only maintain a successful path to addiction recovery, but to address unresolved family issues affecting children and spousal relationships.

\section{Resumen}

El papel de trabajo en el hogar con familias afectadas por el abuso de substancias tiene la oportunidad de confrontar problemas familiares y personales que con regularidad no son muy bien observados por las intervenciones de cuidado que tienen poco contacto la familia y el 
impacto que el abuso de alcohol y otras drogas tienen en el ambiente familiar. Este articulo observa la importancia de envolver a la familia en el proceso de recuperacion y ofrece la ventaja de visitas en el hogar para asistir a la persona que tiene el problema de abuso de substancias con la abstinenda, reintegrarse a la familia, y confrontando problemas familiares que afectan a los niños y matrimonìos y se han dejado sin resolver.

\section{Résumé}

Le rôle du travail à domicile avec parents touchés par I'usage des stupéfiants ou d'alcool semble très prometteur pour faire face aux problèmes qui ne sont pas abordes par les interventions des soins continuatUes. Celles-ci n'impliquent que très peu de contacte avec la famille et les effets que Palcool et l'usage d'autres stupéfiants produisent sur le foyer familial. Cet article résume l'importance d'incorporer la famille dans le procesus du rétablissment, et demontre aussi les avantages comparatifs d'une approche "visitation à domicile" pour aider au toxicomane de continuer d'eviter les druges ou l'alcool, de s'integrer de nouveau dans le foyer familial, et de faire face aux problèmes antérieurs dans la famille touchant les enfants et les relations avec l'époux/épouse.

\section{The authors}

Kenneth J. Gruber, Ph.D. is the Research and Statistical Services Coordinator for School of Human Environmental Sciences, University of North Carolina, Greensboro, North Carolina. He completed his undergraduate work at the University of Virginia in 1974 with a major in psychology and earned a M.A. (1976) and a Ph.D. (1981) in psychology (concentration in social psychology) from the University of North Carolina. Greensboro. His non-university related areas of professional work include evaluation of child and family service programs, development of human services data collection systems, and advocacy for home based intervention programs. He helped Tom Fleetwood develop an in-home substance abuse recovery services program, the Bridges Program, for recovering parents of children at risk of out-of-home placement. His research interests include risk and protective factors relating to adolescents, substance use issues in families, and family environment factors affecting child welfare.

Tom W. Fleetwood, M.S.W., L.CS.W., is the Director of Substance Abuse Services and Clinical Supervision for the Methodist Home for Children located in Raleigh North Carolina. He earned a B.A. in Psychology and Sociology in 1975 and a M.S.W. in 1981 from West Virginia University. He has over 10 years of direct in-home service experience working with families at risk and helping families avoid unnecessary out-of-home placement and is an experienced supervisor of fatnily preservation and substance abuse services for families and adolescents. He is an experienced trainer in substance issues and has been a member of a number of local and regional task forces directed at providing services to substance affected families and individuals. With Dr. Ken Gruber. he developed an in-home substance abuse recovery services program, the Bridges Program, for recovering parents of children at risk of out-of-home placement. His professional life-time goal is to participate in and advocate for the continued development of programs and services related to expanding the application of in-home service to substance affected parents, families, and adolescents. 


\section{References}

Azzi-Lessing, L., Olsen, L. (1996). Substance abuse affected families in the child welfare system: new challenges, new alliances. Soc. Work 41(1):15-23.

Black, M. M., Nair, P. (1994). Parenting and early development among children of drug-abusing women: effects of home intervention. Pediatrics 94(4):440-448.

Brown. B. S., O'Grady, K. E.. Battjes, R. J., Farrell, E. V.. Smith, N. P.. Nurco, D. N. (2001). Effectiveness of a stand-alone aftercare program for drug-involved offenders. J. Subst. Abuse Treat. 21:185-192.

Brown, S.. Lewis. V. (1999). The Alcoholic Family in Recovery: A Developmental Model. New York: Guilford Press.

Carten, A. J. (1996). Mothers in recovery: rebuilding families in the aftermath of addiction. Soc. Work 41(2):214-223.

Chassin, L., Curran. P. J., Hussong, A. M.. Colder, C. R. (1996). The relation of parent alcoholism to adolescent substance use: a longitudinal follow-up study. J. Abnorm. Psychoi 105(1):70-80.

Connors. G. J.. Donovan. D. M., DiClemente. C. C. (2001). Substance Abuse Treatment and Stages of Change. New York: Guilford Press.

Costantini, M. F.. Wermuth. L., Sorensen, J. L., Lyons, J. S. (1992). Family functioning as a predictor of progress in substance abuse treatment. J. Subst. Abuse Treat, 9:331-335.

Daley. D. C. Marlatt. A. G. (1992). Relapse prevention: cognitive and behavioral interventions. In: Lowinson. J. H., Ruiz. P., Millman, R. B., Langrod, J. G., eds. Substance Abuse: A Comprehensive Textbook. Baltimore: Williams \& Wilkins, 533-542.

Daley, D. C, Raskin. M, S. (1991). Relapse prevention and treatment effectiveness studies. In: Daley, D. C, Raskin, M. S., eds. Treating the Chemically Dependent and Their Families. Newbury Park, CA: Sage, 183-196.

De Leon, G., Melnick, G., Tims, F. M. (2001). The role of motivation and readiness in treatment and recovery. In: Tims, F. M., Leukefeld, G. C. Platt. J. J., eds. Relapse and Recovery in Addictions. New Haven: Yale University Press, 143-171.

DeJong, W. (1994). Relapse prevention: an emerging technology for promoting long-term drug abstinence. Int. J. Addictions 29:681-705.

Denning, P. (2001). Strategies for implementation of harm reduction in treatment settings. $J$. Psychoactive Drugs 33(1):23-26.

Donovan, D. M. (1998). Continuing care: promoting the maintenance of change. In: Miller. W. R., Heather, N., eds. Treating Addictive Behaviors. 2nd ed. New York; Plenum Press.

Edwards, M. E., Steinglass, P. (1995). Family therapy treatment outcomes for alcoholism. $J$. Marital Fam. Ther. 21(4):475-509.

Fals-Stewart. W., Birchler, G. R., O'Farrell, T. J. (1996). Behavioral couples therapy for male substance-abusing patients: effects on relationship adjustment and drug-using behavior. $J$. Consul. Clin. Psychoi. 64(5):959-972.

Gilbert, F. S. (1988). The effect of type of aftercare follow-up on treatment outcome among alcoholics. J. Stud. Alcohol 49(2):149-159.

Glantz, M.. Johnson. J. (1999). Resilience and Development. New York: Plenum.

Gorski. T., Miller. M. (1988). Staying Sober Workbook. Independence, MO: Independence Press.

Granfield, R., Cloud. W. (2001). Social context and "natural recovery": the role of social capital in the resolution of drug-associated problems. Subst. Use Misuse 36(11):1543-1570. 
Gray, M. (1993). Relapse prevention. In: Straussner, S. L. A., ed. Clinical Work with SubstanceAbusing Clients. New York: Guilford Press.

Gregoire, K. A., Schultz, D. J. (2001). Substance-abusing child welfare parents: treatment and child placement outcomes. Child Welfare 80(4):433-452.

Gruber, K. J., Fleetwood, T. W., Herring. M. W. (2001). In-home continuing care services for substance-affected families. Soc. Work 46(3):267-277.

Haber. J. (2000). Management of substance abuse and dependence problems in families. In: Naegle. M. A., D'Avanzo. C. E., eds. Addictions \& Substance Abuse: Strategies for Advanced Practice Nursing. New Jersey: Prentice Hall, 305-331.

Hall, E. A., Baldwin. D. M., Prendergast, M. L. (2001). Women on parole: barriers to success after substance abuse treatment. Hum. Organ 60(3):225-233.

Hawkins. J. D., Catalano, R. F. (1985). Aftercare in drug abuse treatment. Int. J. Addictions 20(6\&7):917-945.

Higgins. S. T., Budney, A. J., Bickel, W. K., Badger. G, J. (1994). Participation of significant others in outpatient behavioral treatment predicts greater cocaine abstinence. Am. J. Drug Alcohol Ab. 20(1):47-56.

Hiller, M. L., Knight, K., Simpson. D. D. (1999). Prison-based substance abuse treatment, residential aftercare and recidivism. Addiction 94(6):833-842.

Hohman, M. M., Butt. R. L. (2001). How soon is too soon? Addiction recovery and family reunification. Child Welfare 80(1):53-67.

Killeen, T., Brady, K. T. (2000). Parental stress and child behavioral outcomes following substance abuse residential treatment: follow-up at 6 and 12 months. J. Subst. Abuse Treat. 19(1):23-29.

LaFave. L. M., Echols, L. D. (1999). An argument for choice: an alternative women's treatment program. J. Subst. Abuse Treat. 16(4):345-352.

Magura, S., Laudet. A. B. (1996). Parental substance abuse and child maltreatment: review and implications for intervention. Child Youth Serv. Rev. 18(3): 193-200.

Margolis, R. D., Zweben, J. E. (1998). Treating Patients with Alcohol and Other Drug Problems. Washington D.C.: American Psychological Association.

Marlatt, G. A.. Blume. A. W., Parks, G. A. (2001). Integrating harm reduction therapy and traditional substance abuse treatment. J. Psychoactive Drugs 33(1): 13-21.

Marlatt, G. A.. Tapert. S. F. (1993). Harm reduction: reducing the risks of addictive behaviors. In: Baer, J. S., Marlatt, G. A., McMahon, R. J., eds. Addictive Behaviors Across the Lifespan. Newbury Park, CA: Sage Publications, 243-273.

Marlatt, G. A., Witkiewitz, K. (2002). Harm reduction approaches to alcohol use: health promotion, prevention, and treatment. Addict. Behav. 27:867-886.

McAlpine, C, Marshall, C. C. Doran, N. H. (2001). Combining child welfare and substance abuse services: a blended model of intervention. Child Welfare 80(2):129-149.

McCrady, B. S., Epstein, E. E. (1996). Theoretical bases of family approaches to substance abuse treatment. In: Rotger, F., Kekker, D. S., Morganstern. J.. eds. Treating Substance Abuse: Theory and Technique. New York: Guilford Press. 117-142.

McCubbin, H. I., McCubbin, M. A., Thompson, A. I., Han, S. (1999). Contextualizing family risk factors for alcoholism and alcohol abuse. J. Stud. Alcohol (suppl 13):75-78.

McEldowney, R. P., Heilman. J. G. (1999). Evaluation of substance abuse treatment in the era of managed care: the role of cost benefit analysis. In: Tucker, J. A., Donovan, D. M., 
Marlatt, G. A., eds. Changing Addictive Behavior: Bridging Clinical and Public Health Strategies. New York: Guilford Press, 344-365.

McKay, J. R. (2001). Effectiveness of continuing care interventions for substance abusers: implications for the study of long-term treatment effects. Evaluation Rev. 25(2):211-232.

Moore, J., Finkelstein, N. (2001). Parenting services for families affected by substance abuse. Child Welfare 80(2):221-238.

Nelson-Zlupko, L., Dore. M. M., Kauffman, E., Kaltenbach. K. (1996). Women in recovery: their perceptions of treatment effectiveness. J. Subst. Abuse Treat. 13(1):51-59.

O'Farrell, T. J., Choquette, K. A., Cutter. H. S. G.. Brown. E. D., McCourt, W. F. (1993). Behavioral marital therapy with and without additional couples relapse prevention sessions for alcoholics and their wives. J. Stud. Alcohol 54(6):652-666.

O'Farrell, T. J., Fals-Stewart. W. (1999), Treatment models and methods: family models. In: McCrady, B. S.. Epstein, E. E., eds. Addictions: A Comprehensive Guidebook. New York: Oxford University Press, 287-305.

O'Farrell, T. J., Feehan. M. (1999). Alcoholism treatment and the family: do family and individual treatments for alcoholic adults have preventive effects for children? J. Stud. Alcohol (suppl. 13):125-129.

Olsen, L, J. (1995). Services for substance abuse-affected families: the project connect experience. Child Ado. Soc. Work J. 12(3):183-196.

Patterson, D. G., MacPherson, J., Brady. N. M. (1997). Community psychiatric nurse aftercare for alcoholics: a five-year follow-up study. Addiction 92(4):459-468.

Prochaska, J. O., DiClemente, C. C, Norcross. J. C. (1992). In search of how people change: applications to addictive behaviors. Amer. Psych. 41:1102-1114.

Semidei, J., Radel. L. F., Nolan, C. (2001). Substance abuse and child welfare: clear linkages and promising responses. Child Welfare 80(2):109-128.

Sheridan, M. J. (1995). A proposed intergenerational model of substance abuse, family functioning, and abuse/neglect. Child Abuse Neglect 19(5):519-530.

Steinglass. P., Bennett. L. A.. Wolin, S. J., Reiss, D. (1987). The Alcoholic Family. New York: Basic Books.

Stevens-Smith, P. (1998). Maintaining behavior change: relapse prevention strategies. In: Stevens-Smith, P., Smith, R. L., eds. Substance Abuse Counseling: Theory and Practice. New Jersey: Prentice Hall.

Substance Abuse and Mental Health Services Administration. (2002). Results from the 2001 National Household Survey on Drug Abuse: Volume I. Summary of National Findings. Rockville: Office of Applied Studies. NHSDA, Series H-17, DHHS Publication No. SMA 02-3758. [Also available at http://www.samhsa.gov/oas/pOOOOO16.htm\#standard].

Sullivan, W. P., Wolk, J. L., Hartmann, D. J. (1992). Case management in alcohol and drug treatment: improving client outcomes. Fam, Soc-J. Contemp. H. 73(4): 195-202.

Tracey, E. M. (1994). Maternal substance abuse: protecting the child, preserving the family. Soc. Work 39(5):534-540.

Uziel-Miller. N. D., Lyons, J. S. (2000). Specialized substance abuse treatment for women and their children: an analysis of program design. J. Subst. Abuse Treat. 19(4):355-267.

Voydanoff. P.. Donnelly, B. W. (1998). Parents' risk and protective factors as predictors of parental well-being and behavior. J. Marriage Fam. 60(May):344-355.

Walsh, F. (1998). Strengthening Family Resilience. New York: Guilford Press. 
Walton, M. A., ReischI, T. M., Ramanthan, C. S. (1995). Social settings and addiction relapse. J. Subst. Abuse 7(2):223-233.

Whiteside-Mansell, L., Crone, C. C, Connors, N. A. (1999). The development and evaluation of an alcohol and drug prevention and treatment program for women and children. J. Subst. Abuse Treat. 16(3):265-275.

Wynne, R, D.. McCrady. B. S.. Kahler, C. W., Liddle. H. A., Palmer, R. B., Horberg, L. K., Schlesinger, S. E. (1996). When addictions affect the family. In: Harway, M., ed. Treating the Changing Family. New York: John Wiley \& Sons, 293-317. 